\title{
MONTHLY DESIGN DATA FOR MAXIMUM SOLAR RADIATION FALLING ON COLLECTOR ARRAYS IN BAGHDAD CITY
}

\author{
Ali Naser Hussien ${ }^{*}$
}

\begin{abstract}
Increasing use of solar energy as a clean and free solution for energy demand necessitates proper use of its equipment, enhanced spatial planning and distribution of solar collectors, optimum directional facing and tilt angle to ensure maximum solar radiation falling, and decreasing as possible as the shading effects of panel arrays. Most existing references lack comprehensive data about shading effects that varied along the year and design of solar array. In the present work, enhanced theoretical design data of solar collector arrays were tabulated for each month in Baghdad. MATLAB program was used to calculate the maximum clear sky solar radiation per unit area per day. The tabulated data yields an economically saved design of solar field or rooftop collector systems. The results indicated that, the shading effect on panel arrays almost vanishes when the distance between two panel rows to panel height ratio is greater than 1 in summer and greater than 2 in winter.
\end{abstract}

\section{Keywords: Solar field designs; panel shading effect; solar collector arrays; mutual shading.}

\section{INTRODUCTION}

Shading on solar collector panel arrays has a big role in decreasing absorbed solar energy. Collectors facing sunrays continuously absorb maximum energy. This condition can be achieved by using tracking systems but they are non-economical, so that, determining the optimum tilt angle with chooses the appropriate distance between panel arrays lead to reduce the shading losses and increase the rate of energy absorbed. These two factors (optimum tilt angle and distance between panel arrays) vary along the year; and must be adjusted for different intervals, i.e. monthly or seasonally. Optimum tilt angle of collectors in Kirkuk, Baghdad, and Nasiriya cities in Iraq calculated by Sultan, et al [1], using ASHRAE model, to evaluate the highest monthly average solar radiation per day for south facing collector associated to these angles, also they reported in their study a measured radiation values on tilted surfaces. They concluded that the optimum monthly tilt angles of Baghdad are between $56.5^{\circ}$ in December and $9.8^{\circ}$ in June, but their study did not include shading effects. Many researchers have studied the effect of shading associated to their region. Significant influence of shading is limited to winter season at Sweden latitude is deduced by Passias and Kallback [2] and the distance between panels array to panel height ratio greater than 2 decreases energy losses. Reduction in power from current-voltage chart measured by Quaschning and Hanitsch [3] and concluded that great energy lost by shading on photovoltaic panel. Also simulated the shading losses in Berlin for different P. V. panel arrangements on flat roof, and concluded that $50 \%$ of energy can be increased by changing the cell connections and increase the number of panels, by reasonable tilt angle and distance between rows choice Quaschning and Hanitsch [4].

Method of average value of shading factor on collector rows of solar field presented by Elsayed and Turki [5]. They used the dimensionless ratios of the solar panels in the field and geometrical analysis of them using separation of variables, and scale factors. Charts of sun path employed by Vignola, [6] to estimate the energy lost by shading and compared with the PV system performance.

Optimizing the tilt angle, panel facing, and distance between PV panel rows are suggested by Jouri, and Henrik, [7], for Lund and Miami cities, using a simulation program, they concluded that the maximum annual output can be achieved by choosing 0 inclination without spaces between rows. Similar aspects studied by Weissenbacher, [8], and Castellano, et al, [9]

In Baghdad city, where large number of sunny days during year, calculation of solar energy from collector panel array is very important to obtain the optimum array output. The aims of present work are:

1. calculation of the optimum tilt angle of the panel for each month in Baghdad city. 
2. calculation of the absorbed energy from solar arrays at optimum tilting, considering the shading effects on all rows behind the first row.

3. construction of data table includes maximum possible solar radiation per unit area per day in Baghdad for each month, used for solar field or rooftop system design.

\section{CALCULATION METHODS}

ASHRAE's clear sky model for solar radiation on inclined surfaces with modified A, B, and C constants is used in this paper because it offers a simpler algorithm, and suitable method for engineering calculations [10]. The model includes the evaluation of the hourly beam and diffuse radiations, which are calculated after finding the solar time and position, as follows:

\section{Calculation of the solar altitude angle and the incidence angle}

The solar altitude angle $(\alpha)$ and the angle of incidence $(\theta)$ are (ASHRAE Fundamentals Handbook [11])

$$
\begin{aligned}
& \sin \alpha=\cos \emptyset_{L} \cos \delta \cos \omega+\sin \emptyset_{L} \sin \delta \\
& \cos \theta=\cos \alpha \cos \gamma \sin \beta+\sin \alpha \cos \beta
\end{aligned}
$$

where; $\phi_{L}$ is the latitude angle of the location $\left(33.3^{\circ} \mathrm{N}\right.$ for Baghdad), $\beta$ is the tilt angle of the surface $\left(90^{\circ}\right.$ for vertical surface and $0^{\circ}$ for horizontal), and $\gamma$ is the surface azimuth angle (equal zero for south direction), whereas $\delta$ is the solar declination angle, and calculated as a function of number of day in the year by Duffie and Beckman [12]as:

$$
\delta=23.45 \sin [360 *(284+N) / 365]
$$

The hour angle $\omega$ (in degrees), measured from solar noon, calculated as:

$$
\omega=15 *(A S T-12)
$$

where AST is the apparent solar time, calculated from the equation:

$$
A S T=L T+4(T Z+L O N G)+E Q T(N)
$$

where $\mathrm{LT}$ is the local time, $\mathrm{LONG}$ is the local longitude $\left(44.4^{\circ} \mathrm{E}\right), \mathrm{TZ}$ is the standard meridian for local time zone $\left(45^{\circ} \mathrm{E}\right)$, and EQT $(\mathrm{N})$ is the equation of time, evaluated by Duffie and Beckman [12] as:

$$
E Q T(N)=9.87 \sin 2 b-7.53 \cos b-1.5 \sin b
$$

where;

$$
b=360 * \frac{N-81}{364}
$$

\section{Calculation of the direct normal solar radiation}

The direct normal solar radiation $I_{D N}$ is (Lunde [13]):

$$
I_{D N}=A / \exp \left(\frac{B}{\sin \alpha}\right)
$$

Where, $\mathrm{A}$ is the apparent solar radiation $\left(\mathrm{W} / \mathrm{m}^{2}\right)$, at air mass $=1$, and $\mathrm{B}$ is the atmospheric extinction coefficient. The values of A and B calculated by Joudi [14] suggestion for any day $\mathrm{N}$ of the year, as;

$$
A=1158 *\left[1+0.066 \cos \left(360 * \frac{N}{370}\right)\right]
$$


Journal of Thermal Engineering, Technical Note, Vol. 6, No. 2, Special Issue 11, pp. 41-52, March, 2020

$$
B=0.175[1-0.2 \cos (0.93 N)]-0.0045[1-\cos (1.85 N)
$$

\section{Calculation of the global, beam and diffuse radiation}

The following relation can find the component of beam radiation on a surface for a certain incident angle (ASHRAE Fundamentals Handbook [11]):

$$
I_{b}=I_{D N} \cos \theta
$$

Whereas Farber and Morrison [15] presented the diffuse solar radiation $\left(I_{d}\right)$ as:

$$
I_{d}=C * I_{D N}(1+\cos \beta) / 2
$$

where $\mathrm{C}$ is the diffused to direct normal averaged ratio (dimensionless) that calculated according to Joudi [14] for any day of the year, as;

$$
C=0.0965\left[1-0.42 \cos \left(\frac{360 N}{370}\right)\right]-0.0075[1-\cos (1.95 N)]
$$

The global solar irradiance $I_{G}$ for tilted panel without shading (usually first row in solar feild) with neglect the ground reflectance can be calculated (Lunde [13]) as:

$$
I_{G}=I_{b}+I_{d} \quad \frac{W}{m^{2}}
$$

Calculating this global falling energy for the 24 hours (zero hour energies before sun rise and after sunset) of the monthly average days, then summing of these hour energies along one average day, and multiplying by 0.0036 to obtain the average energy incidence per solar day in a certain month in $\mathrm{MJ} / \mathrm{m}^{2}$-day, and as follows:

$$
\overline{E_{G}}=\left(I_{G) 1}+I_{G) 2}+\cdots \ldots \ldots \ldots \ldots I_{G) 24}\right) * 0.0036 \quad M J / m^{2} \text { day }
$$

\section{Solar radiation on shaded panels}

For shaded panel, Fig. (1) shows the area of back row that shaded by the front row, the length $L_{s h}$ and the height $H_{s h}$ of this shaded area calculated as (Bara et al [16]):

$$
\begin{aligned}
& L_{s h}= \begin{cases}L-(\text { dis } * \sin \beta \cos \delta \sin \omega) / \cos \theta & \text { when } L_{s h} \geq 0 \\
0 & \text { when } L_{s h}<0\end{cases} \\
& H_{s h}= \begin{cases}H-(\text { dis } * \sin \alpha) / \cos \theta & \text { when } H_{s h} \geq 0 \\
0 & \text { when } H_{s h}<0\end{cases}
\end{aligned}
$$

where $\mathrm{L}, \mathrm{H}$ and dis, are the collector panel width and height and the distance between collector rows respectively.

The shaded area is:

$$
A_{s h}=L_{s h} * H_{s h}
$$


Journal of Thermal Engineering, Technical Note, Vol. 6, No. 2, Special Issue 11, pp. 41-52, March, 2020

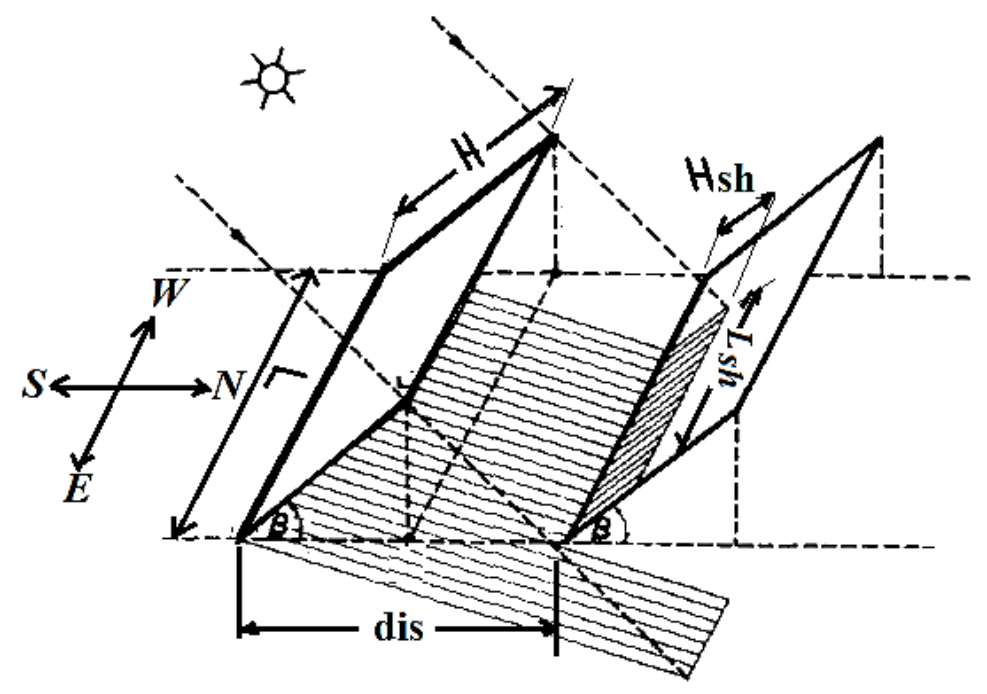

Figure 1 The shaded area on back row by the front row

This area must be subtracted from all solar panel areas except the panels of the first row to evaluate the value of the direct beam energy falling on the collector panels. Therefore the direct irradiance for the shaded solar panel per unit area $\mathrm{I}_{\mathrm{bsh}}$ is:

$$
I_{b s h}=\left[\left(A_{c}-A_{s h}\right) * I_{b}\right] / A_{c} \quad \frac{W}{m^{2}}
$$

To evaluate the decrease in diffuse irradiance by shading effect on rows except the first row, shading angle $\xi$ and its average must be calculated, referring to Fig. 2, $\xi$ and $\bar{\xi}$ are calculated as (Appelbaum and Bany [17]):

$$
\begin{gathered}
\xi(x)=\tan ^{-1}[(H-x) \sin \beta /(\text { dis }-H \cos \beta+x \cos \beta)] \\
\bar{\xi}=\frac{1}{H} \int_{0}^{H} \xi(x) d x
\end{gathered}
$$

The result of this integration can be written as (Passias and Kallback,[1]):

$$
\bar{\xi}=\sin \beta \frac{d i s}{H}\left[\begin{array}{c}
\tan \beta \tan ^{-1}\left(\frac{H \sin \beta}{d i s-H \cos \beta}\right)+\ln \left|1+\frac{H \cos \beta}{d i s-H \cos \beta}\right|- \\
\frac{1}{2} \ln \left\{1+\left(\frac{H \cos \beta}{d i s-H \cos \beta}\right)^{2}\right\}-\frac{\tan ^{-1}\{H \sin \beta / \text { dis }-H \cos \beta\}}{\sin \beta \cos \beta\{1+H \cos \beta /(\text { dis }-H \cos \beta)\}}
\end{array}\right]
$$

Therefore, the diffuse irradiance taking into account the shading effect, can be calculated as (Jones, and Burkhart [18]):

$$
I_{d s h}(\beta, \bar{\xi})=C I_{D N}\left\{\cos ^{2}(\beta / 2)+\cos ^{2}(\bar{\xi} / 2)-1\right\}
$$

Also the global irradiance of shaded panels $\mathrm{I}_{\mathrm{Gsh}}$ with neglect the ground reflectance is:

$$
I_{G s h}=I_{b s h}+I_{d s h}(\beta, \bar{\xi}) \quad \frac{W}{m^{2}}
$$




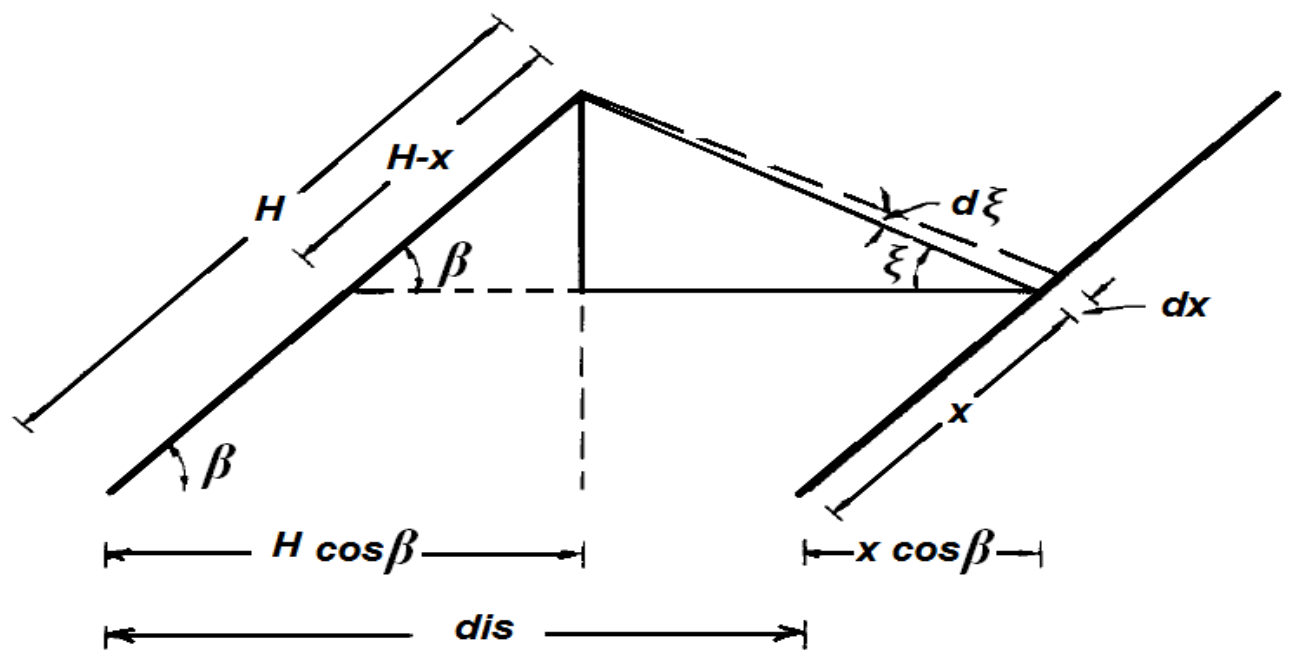

Figure 2 Schematic diagram illustrate the angle $\xi$

Similar to equation (14), the average incident energy per area per solar day, for shaded panel, in a certain month, in $\mathrm{MJ} / \mathrm{m}^{2}$-day can be calculated as:

$$
\overline{E_{G s h}}=\left(I_{G s h) 1}+I_{G s h) 2}+\cdots \ldots \ldots \ldots I_{G s h) 24}\right) * 0.0036 \quad M J / m^{2} . d a y
$$

And the total monthly average incident energy per solar day by neglecting the ground reflectance for the solar field, $\overline{E_{t f}}$ of $\mathrm{n}$ row and $\mathrm{m}$ panel in each row is:

$$
\overline{E_{t f}}=\overline{E_{G}} * m+\overline{E_{G s h}} * m *(n-1) \quad M J / m^{2} . d a y
$$

This energy calculated for Baghdad city, for each month by calculate the incident irradiance of average day in that month, these average days were presented by Klein, [19], and illustrated in table 1 below.

\begin{tabular}{|c|c|c|c|c|c|c|c|c|c|c|c|c|}
\hline Day of the month & 17-Jan & 16-Feb & 16-Mar & 15-Apr & 15-May & 11-Jun & 17-Jul & 16-Aug & $15-\operatorname{Sep}$ & $15-O c t$ & $14-$ Nov & $10-\mathrm{Dec}$ \\
\hline $\begin{array}{c}\text { Day sequence in } \\
\text { the year }\end{array}$ & 17 & 47 & 75 & 105 & 135 & 162 & 198 & 228 & 258 & 288 & 318 & 344 \\
\hline
\end{tabular}

Table 1. Days of average monthly solar radiation [19]

Assume the distance between rows to panel height ratios $(\mathrm{r}=d i s / H)$ are begins with $\mathrm{r}=0.5$ to $\mathrm{r}=3$ with 0.25 interval. Whereas the collector tilt angles to be $\left(0^{\circ}\right.$ to $70^{\circ}$ with $5^{\circ}$ interval $)$, to cover the range of maximum possible solar radiation.

\section{RESULTS AND DISCUSSIONS}

It is worth mentioning, that all results for Baghdad in this paper are calculated mathematically using MATLAB in the north hemisphere of the earth and the collectors face the south direction. The model of calculation is the ASHRAE clear sky radiation model, with modified constant values (A, B, and C).

Radiation values per collector area $\left(\mathrm{A}_{\mathrm{c}}\right)$ per day vs. collector tilt angle for different row spacing's to panel height ratio (r) in every month in a year are shown in figures 3,4 , and 5 . The values in these figures calculated by summing the radiation for each hour in the monthly average day using Eq. (14) for unshaded first row and Eq. (24) for shaded rows, these calculations were repeated for the range of tilt angles between $0^{\circ}$ to $70^{\circ}$ with $5^{\circ}$ interval and for $\mathrm{r}$ - values between 0.5 to 3 with 0.25 interval.

Clearly from these figures, the sharp reduction in radiation of the panels behind the unshaded first row at $0^{\circ}$ tilt angle, and $r$ - values less than 1, i.e. $r=0.5$ and 0.75 . This reduction is due to the hiding of 0.5 panel area 
when $r=0.5$ and 0.25 panel area when $r=0.75$ by the front panel at $0^{\circ}$ tilt angle, and this condition must be avoided in design of solar field.

The high sun altitude in Baghdad city in summer season compared to the winter made the optimum inclination of unshaded panel (usually first row panel) in summer is between $0^{\circ}$ and $15^{\circ}$ (the months; June, July, and August) and between $50^{\circ}$ and $60^{\circ}$ in winter (the months; December, January, and February). Whereas the tilt angles in spring months (March, April, and May) and autumn months (September, October, and November) are between summer and winter ranges, as shown in Figs. 3, 4, and 5.

The same cause (high sun altitude) makes shading effect in summer is approximately vanished when $r$ value (distance between row and row (dis) over panel height $(\mathrm{H})$ ) is higher than 1 compared to $\mathrm{r}$ equal and higher than 2 when shading approximately vanishes in winter. Therefore, the curves of radiation per unit area per day via tilt angle appear approximately identical for $r$ - values greater than 0.75 in figure 4 in May, June, July, and August and greater than 1.75 in figures 3 and 5 in November, December, and January.

This means that more panel can be used with more radiation values in the same location in summer compared to the other seasons.

The third object of the present work that mentioned previously, involves construction of data table contains the maximum possible radiation per square meter per day with the associated tilt angles and $r$-values for every month. Table (2) represent this design data table and it is the summarization of the results of figures 3,4 , and 5.

\section{Using table 2 in design}

As mentioned above, table 2 represent the summarization of the results extracted from Figs. (3, 4, and 5). Clearly, from table 2, the first column represents the months of the year, the second column represents the corresponding optimum tilt angle of the panels, and the third column indicates the corresponding maximum possible radiation value per unit area per day of the first unshaded row. Whereas the remainder columns gives maximum possible radiation value per unit area per day for shaded row according to $r$ - values.

Energy absorbed by solar field or rooftop system is the summation of first unshaded row energy and energy of shaded rows behind it, so the maximum possible absorbed energy in a certain month can be calculated by the summation of energy value from third column of table 2 at this month plus the multiplication of the number of shaded rows by energy value of shaded row selected from table 2 according to r- value. Multiply the summation by the collector area gives the total energy of solar field or rooftop system.

For a certain spatial area and a certain collector dimensions, number of rows and $\mathrm{r}$ - values are related to each other, increasing the number of collector rows means decreasing in $r$ - value, and vase versa, also as $r-$ value decreases, shading effects increases and absorbed energy per collector area decreases, and vase versa, therefore, the selection of $\mathrm{r}$ - value and the number of rows have a significant impact in economical design and best utilization of solar energy equipment. This economical design contributes in reduction of construction and operational costs of equipment. Illustrative example in appendix A presents more details about the design data of table 2 and appropriate selection of $\mathrm{r}$ - values.

\section{Comparison of the results with previous works}

The only maximum radiation values of monthly average days per unit area for the first unshaded row and the associated optimum inclination that listed in table 2 of present work can be compared with previous works because there is not any data or any study to shaded effects on panel array for Baghdad or any region in Iraq. These maximum radiations with their associated tilt angle are compared with the corresponding measured data of the literature Sultan, et al [1], which is the average of measured previous data between the years (1981-1985) and the optimum tilt angle resulted in it. The comparison is indicated in table (3), and appears convergence of the optimum inclination results, the difference between two studies does not exceed $5^{\circ}$ for all months, except for May and July the differences are $9^{\circ}$ and $7^{\circ}$ respectively.

The differences are due to use of modified constants (A, B, and C) of ASHRAE model in present study and based constants of ASHRAE model in study of Sultan, et al [1]. In other hand the maximum radiation values comparison indicated some convergence for April, May, June, July, August, and September (hot months) whereas the difference increases in February, March, October, and November, and more divergence in December and January. 
Journal of Thermal Engineering, Technical Note, Vol. 6, No. 2, Special Issue 11, pp. 41-52, March, 2020

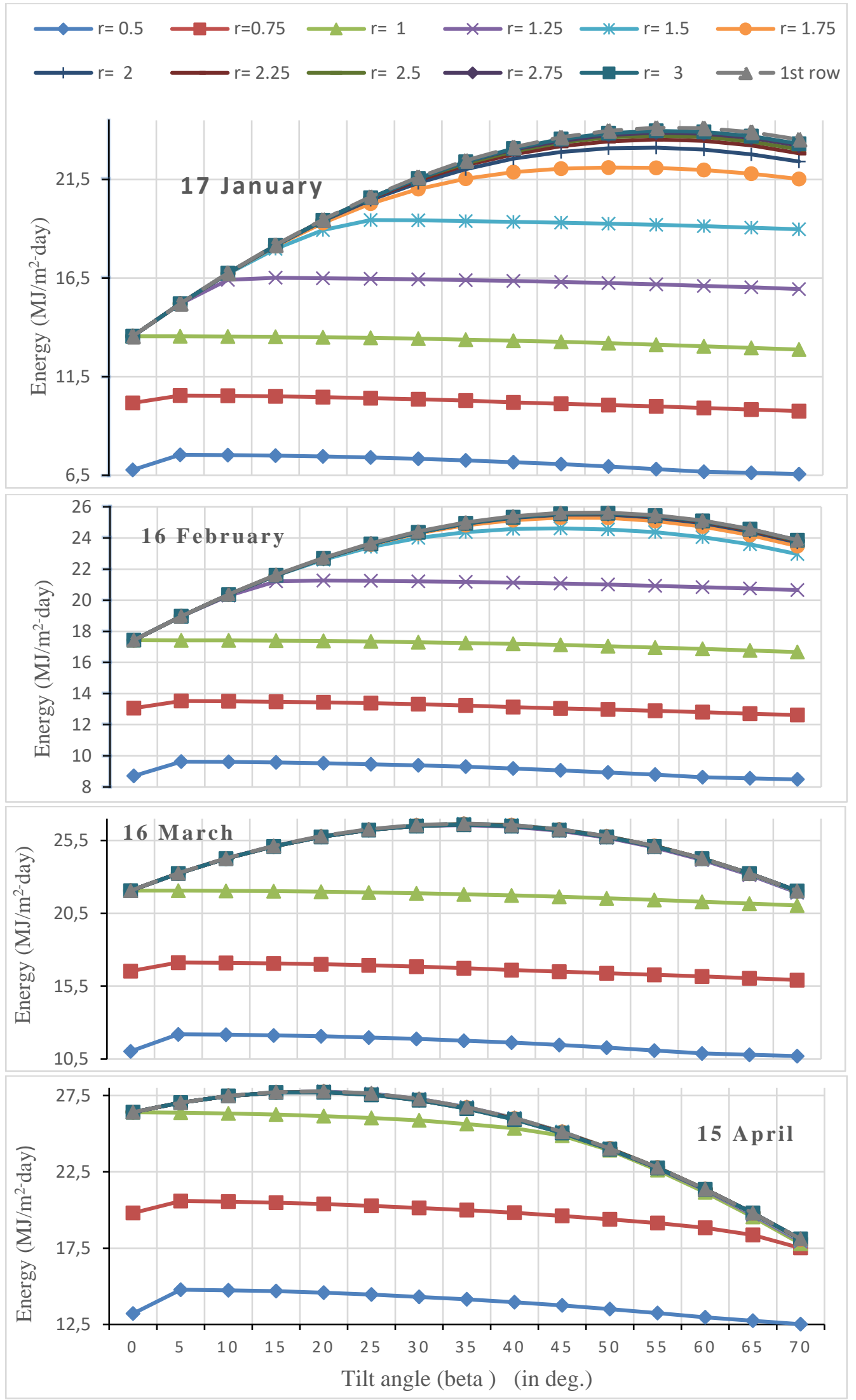

Figure 3 monthly average solar radiation energy values per collector area per day for shaded and unshaded $1^{\text {st }}$ row at different tilt angles and different space to collector height ratio (r) for Jan., Feb., Mar., and Apr. for Baghdad city 
Journal of Thermal Engineering, Technical Note, Vol. 6, No. 2, Special Issue 11, pp. 41-52, March, 2020
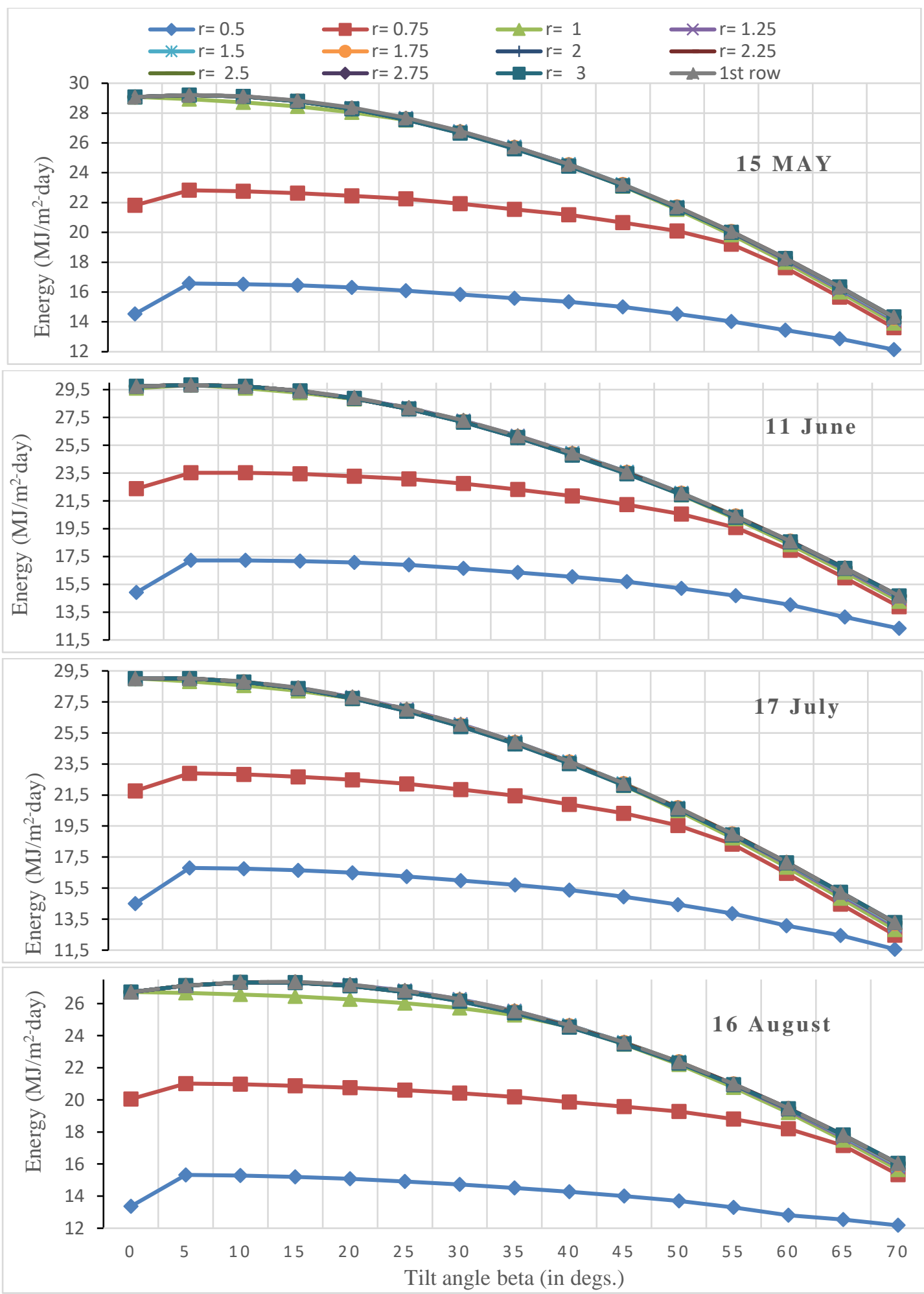

Figure 4 monthly average solar radiation energy values per collector area per day for shaded and unshaded $1^{\text {st }}$ row at different tilt angles and different space to collector height ratio (r) for May., Jun., Jul., and Aug. for

Baghdad city

These differences between two studies in maximum radiation values are due to use clear sky model in present study and average measured data in the article of Sultan, et al [1], that take into account the dust effect in hot months and the cloud effect in winter months. In general, the clear sky model is satisfied model to suggest the solar collector array design, because there isn't any specified formula to consider the cloudy and dusty hours, and these weather conditions are randomly occurring. 
Journal of Thermal Engineering, Technical Note, Vol. 6, No. 2, Special Issue 11, pp. 41-52, March, 2020

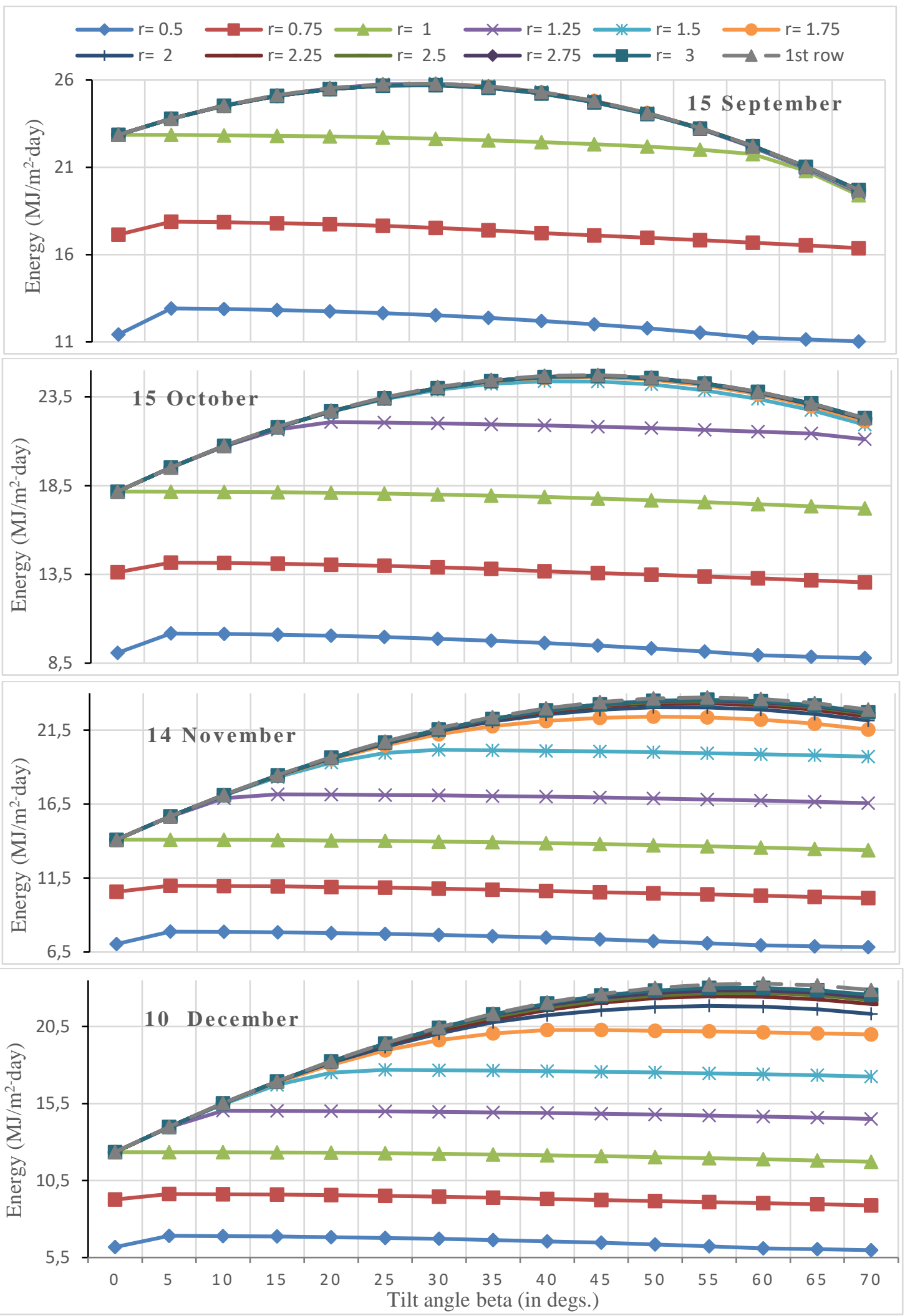

Figure 5 monthly average solar radiation energy values per collector area per day for shaded and unshaded $1^{\text {st }}$ row at different tilt angles and different space to collector height ratio (r) for Sep., Oct., Nov., and Dec. for Baghdad city 
Journal of Thermal Engineering, Technical Note, Vol. 6, No. 2, Special Issue 11, pp. 41-52, March, 2020

Table 2. The maximum possible radiation value in $\left(\mathrm{MJ} / \mathrm{m}^{2}\right.$.day) for $1^{\text {st }}$ unshaded row and shaded row behind it for different $r$ - values, for each month, with associated tilt angle $(\beta)$, in Baghdad city.

\begin{tabular}{|c|c|c|c|c|c|c|c|c|c|c|c|c|c|}
\hline \multirow{2}{*}{ Month } & \multirow{2}{*}{$\begin{array}{c}\beta_{\text {opt }} \\
(.)\end{array}$} & $\begin{array}{c}1^{\text {st }} \\
\text { unshaded } \\
\text { row }\end{array}$ & $\mathrm{r}=0.5$ & $\mathrm{r}=0.75$ & $\mathrm{r}=1$ & $\mathrm{r}=1.25$ & $\mathrm{r}=1.5$ & $\mathrm{r}=1.75$ & $\mathrm{r}=2$ & $\mathrm{r}=2.25$ & $\mathrm{r}=2.5$ & $\mathrm{r}=2.75$ & $\mathrm{r}=3$ \\
\hline Jan & 55 & 24.13 & 6.82 & 9.99 & 13.12 & 16.18 & 19.20 & 22.09 & 23.11 & 23.53 & 23.72 & 23.87 & 23.97 \\
\hline Feb & 50 & 25.63 & 8.94 & 12.98 & 17.04 & 21.00 & 24.55 & 25.29 & 25.50 & 25.55 & 25.58 & 25.59 & 25.58 \\
\hline Mar & 35 & 26.67 & 11.77 & 16.74 & 21.81 & 26.55 & 26.65 & 26.63 & 26.62 & 26.61 & 26.60 & 26.59 & 26.59 \\
\hline APR & 20 & 27.79 & 14.59 & 20.39 & 26.16 & 27.77 & 27.75 & 27.73 & 27.73 & 27.72 & 27.72 & 27.72 & 27.72 \\
\hline May & 5 & 29.21 & 16.58 & 22.82 & 28.93 & 29.21 & 29.21 & 29.21 & 29.21 & 29.21 & 29.21 & 29.21 & 29.21 \\
\hline Jun & 5 & 29.84 & 14.92 & 22.38 & 29.84 & 29.84 & 29.84 & 29.84 & 29.84 & 29.84 & 29.84 & 29.84 & 29.84 \\
\hline Jul & 5 & 29.03 & 16.80 & 22.90 & 28.83 & 29.02 & 29.02 & 29.02 & 29.02 & 29.02 & 29.02 & 29.02 & 29.02 \\
\hline Aug & 15 & 27.36 & 15.20 & 20.87 & 26.45 & 27.34 & 27.32 & 27.32 & 27.31 & 27.31 & 27.31 & 27.31 & 27.31 \\
\hline Sep & 30 & 25.80 & 12.52 & 17.53 & 22.64 & 25.79 & 25.77 & 25.75 & 25.73 & 25.72 & 25.71 & 25.71 & 25.70 \\
\hline Oct & 45 & 24.73 & 9.50 & 13.58 & 17.77 & 21.83 & 24.37 & 24.61 & 24.69 & 24.69 & 24.68 & 24.68 & 24.67 \\
\hline Nov & 55 & 23.71 & 7.10 & 10.39 & 13.65 & 16.82 & 19.94 & 22.37 & 23.04 & 23.31 & 23.45 & 23.51 & 23.55 \\
\hline Dec & 60 & 23.28 & 6.09 & 9.03 & 11.88 & 14.65 & 17.40 & 20.12 & 21.79 & 22.43 & 22.68 & 22.84 & 23.00 \\
\hline
\end{tabular}

Table.3 The comparison between the present work results of unshaded row with previous works

\begin{tabular}{|c|c|c|c|c|c|c|c|c|c|c|c|c|c|c|}
\hline \multicolumn{3}{|c|}{ Month } & Jan. & Feb. & Mar. & Apr. & May & Jun. & Jul. & Aug. & Sep. & Oct. & Nov. & Dec. \\
\hline \multirow{2}{*}{$\begin{array}{c}\text { Present } \\
\text { work }\end{array}$} & $\beta_{\mathrm{opt}}$ & (.) & 55 & 50 & 35 & 20 & 5 & 5 & 5 & 15 & 30 & 45 & 55 & 60 \\
\hline & Radiation & $\left(\mathrm{MJ} / \mathrm{m}^{2}\right.$.day) & 24.13 & 25.63 & 26.67 & 27.79 & 29.21 & 29.84 & 29.03 & 27.36 & 25.8 & 24.73 & 23.71 & 23.2 \\
\hline \multirow{2}{*}{$\begin{array}{c}\text { Sultan, et al } \\
{[1]}\end{array}$} & $\beta_{\text {opt }}$ & (。 & 53.9 & 45.5 & 35.2 & 23.2 & 14 & 9.8 & 12 & 20.2 & 31.6 & 43 & 52.2 & 56.2 \\
\hline & $n$ & $\left(\mathrm{MJ} / \mathrm{m}^{2} . \mathrm{d}\right.$ & רา & 1775 & 21 & 33 & 2765 & 11 & 27 & 25,17 & 23.77 & 19.8 & 17.58 & 13 \\
\hline
\end{tabular}

\section{CONCLUSIONS}

The design data of table 2 that extracted from graphed results developed in present paper are very useful in selection of number of rows, spacing between them, and the panel dimensions and then in design of solar field or rooftop collector systems. The best tilt angle associated to maximum radiation obtained is $60^{\circ}$ in December and $5^{\circ}$ in June and between them in other months for the unshaded panels. The effect of shading in multi rows solar field almost vanishes when $r$ greater than 1 in summer and greater than 2 in winter.

Selection of a suitable number of rows with $r$ value gives maximum possible radiation value with economic initial and operation cost of solar field.

\section{Nomenclature}

$\begin{array}{ll}\text { A } & \text { Apparent solar radiation }\left(\mathrm{W} / \mathrm{m}^{2}\right), \text { at air mass }=1 . \\ \text { Ac } & \text { Collector area } \\ \mathrm{A}_{\text {sh }} & \text { Shading area } \\ \text { B } & \text { The atmospheric extinction coefficient } \\ \mathrm{C} & \text { Average ratio of diffuse to direct normal radiation } \\ \mathrm{H} & \text { Collector height } \\ \mathrm{H}_{\text {sh }} & \text { Shading height } \\ \text { Dis } & \text { Distance between row and row } \\ \text { L } & \text { Collector length } \\ \mathrm{L}_{\text {sh }} & \text { Shading length } \\ \mathrm{I}_{\mathrm{DN}} & \text { Direct normal solar radiation } \\ \mathrm{N} & \text { Day number in the year } \\ \text { AST } & \text { Apparent solar time } \\ \text { LT } & \text { Local time }\end{array}$


TZ Standard meridian for local time zone

LONG Local longitude

EQT Equation of time

$\mathrm{I}_{\mathrm{b}} \quad$ Beam radiation

$\mathrm{I}_{\mathrm{d}} \quad$ Diffuse radiation

$\mathrm{I}_{\mathrm{bsh}} \quad$ Beam radiation of shaded panel

$\mathrm{I}_{\mathrm{dsh}} \quad$ Diffuse radiation of shaded panel

$\mathrm{I}_{\mathrm{G}} \quad$ Total radiation

$\mathrm{m} \quad$ Number of panel in each row

$\mathrm{n} \quad$ Number of rows

$\mathrm{I}_{\mathrm{Gsh}} \quad$ Total radiation of shaded panel

$\overline{E_{G}} \quad$ Total falling energy for the hours of the monthly average days

$\overline{E_{G s h}} \quad$ Total falling energy for the hours of the monthly average days on shaded panel

$\overline{E_{t f}} \quad$ Total falling energy for the hours of the monthly average days on all field panels

r

Distance between two rows to collector height ratio (dis/H)

Greek symbols

$\begin{array}{ll}\alpha & \text { Altitude angle } \\ \beta & \text { Collector tilt angle } \\ \gamma & \text { Surface azimuth angle } \\ \delta & \text { Declination angle } \\ \xi & \text { Shading angle } \\ \bar{\xi} & \text { Average shading angle } \\ \phi_{L} & \text { Latitude angle } \\ \theta & \text { Incidence angle } \\ \omega & \text { Hour angle }\end{array}$

\section{References}

[1] Sultan, F., Ali F. A., and Razaq, T. K., "Tilt Angle Optimization of Solar Collectors for Maximum Radiation in Three Iraqi cities," International Journal of Engineering and Industries(IJEI), vol. 3, no. 4, pp. 99-107, December 2012.

[2] Dimitrios Passias and Bengt Kallback, "Shading Effects in Rows of Solar Cell Panels," Solar Cells, no. 11, pp. 281-291, 1984.

[3] Volker Quaschning and Rolf Hanitsch, "Shade Calculations in Photovoltaic System," in ISES Solar World Conference, Harare / Zimbabwe, September 11-15, 1995.

[4] Volker Quaschning and Rolf Hanitsch, "Increased Energy Yield of 50\% at Flat Roof and Field Installations with Optimized Module Structures," in 2nd World Conference and Exhibition on Photovoltaic Solar Energy Conversion, Vienna · Austria, 6-10 July 1998.

[5] Elsayed, Moustafa M. and Al-Turki, Abdullah M., "Calculation of Shading Factor for a Collector Field," Solar Energy, vol. Vol. 47, no. No. 6, p. 413-424, 1991.

[6] Vignola, F., "Using Sun Path Charts to Estimate the Effect of Shading on PV Arrays," in American Solar Energy Society Conf, Portland, OR., 2004.

[7] Jouri Kanters and Henrik Davidsson , "Mutual shading of PV modules on flat roofs: a parametric study," Energy Procedia, no. 57, p. 1706 - 1715, 2014.

[8] Weissenbacher, M., Towards New Renewable Energy Policies in Urban Areas: The Re-definition of Optimum Inclination of Photovoltaic Panels, J. sustain. dev. , "energy water environ. syst., 3(4), pp 372388,," 2015. [Online]. Available: http://dx.doi.org/10.13044/j.sdewes.2015.03.0028.

[9] Castellano, N. N., J. A. G. Parra, J. Valls-Guirado, and F. Manzano Agugliaro.,, "Optimal displacement of photovoltaic array's rows using a novel shading model," Appl. Energy, vol. 144, pp. 1-9, 2015.

[10] Maleki S. A. M, Hizam H., and Gomes, C., "Estimation of Hourly, Daily and Monthly Global Solar Radiation on Inclined Surfaces: Models Re-Visited," Energies, vol. 10 (1), no. 134, 2017.

[11] ASHRAE 2005, ASHRAE Handbook of Fundamentals, American Society of Heating, Refrigerating, and Air Conditioning Engineers..

[12] J. A. a. B. W. A. Duffie, Solar Energy Thermal Processes, New York: John Wiley and Sons, 1980.

[13] Lunde, P. J., Solar Thermal Engineering Space Heating and Hot Water Systems, New York: John Wiley and Sons, 1980. 
[14] Joudi, K. A., "Some Aspects of Solar Irradiance Calculations," in Proceedings of the 3rd Arab International Solar Energy Conference, SRC, Baghdad, Feb., 1988.

[15] Farber, E. A. Morrison, C. A., "Clear-Day Design Values of Solar Energy," ASHRAE GRP 170, Application of Solar Energy for Heating and Cooling of Buildings, Edited by Jordon, R. C. and Liu, B. Y. H, 1977.

[16] O. Bara, M. Conti and E. Santamata, "Shadows Effect in a Large Scale Solar Power Plant," Sol. Energy, vol. 19, pp. 759-762, 1977.

[17] J. Appelbaum and J. Bany , "Shadow Effect of Adjacent Solar Collectors in Large Scale Systems," Solar Energy, vol. 23, pp. 497-507, 1979.

[18] R. E. Jones, JR. and J. F. Burkhart , "Shading Effects of Collector Rows Tilted Toward The Equator," Solar Energy, vol. 26, pp. 563.-565, 1981.

[19] Klein, S.A., "Calculation of Monthly Average Insolation on Tilted Surfaces," Sol. Energy, vol. 19, p. 325329, 1977.

\section{APPENDIX A}

Illustrative Example: the way to use data of table (2) for design and planning of solar field, determining number of rows and spaces between them and some important notes are illustrated in the following example:

Assume the solar field enough to 6 rows $(n=6)$ of flat panel facing the south direction, distance between two rows to panel height ratio is $1(\mathrm{r}=1)$, and the number of panel in each row is $1,(\mathrm{~m}=1)$ the maximum possible solar radiation according to table 2 and Eq. 25 is calculated as:

$$
\begin{aligned}
\overline{E_{t f}} & =\overline{E_{G}} * m+m *(n-1) * \overline{E_{G s h}} * \quad M J / m^{2} . d a y \\
\text { Or (in Jan.) } & \overline{E_{t f}}=24.13+5 * 13.12=89.75 \quad M J / m^{2} . \text { day }
\end{aligned}
$$

This field is certainly enough to 5 rows with $\mathrm{r}=1.25$, and in the same way maximum energy absorbed is

(in Jan.)

$$
\overline{E_{t f}}=24.13+4 * 16.18=88.86 \quad \mathrm{MJ} / \mathrm{m}^{2} . \text { day }
$$

Let ( 6 row with $r=1$ ) be choice 1 , and ( 5 row with $r=1.25)$ as choice 2 . Table (4) indicates the radiation per unit area per day for two choices, depending on the results of table (2) and the above illustrations. Clearly from table (4) that the results difference percentage for two choices not exceed $17 \%$ in hot months and trivial difference percentage in October, November, December, January, February, and March. When dispensing this difference, choice 2 becomes favorable, and more economy than choice 1, in terms of initial and operation cost reduction of one row of panels, and so on. Therefore, use of table (2) need some attention, and subjected to review.

Table 4. The energy absorbed comparison between two choices ( $\mathrm{n}=6$ with $\mathrm{r}=1)$ and $(\mathrm{n}=5$ with $\mathrm{r}=1.25)$ according to table 2. (MJ/m².day)

\begin{tabular}{|c|c|c|c|c|}
\hline Month & $\beta_{\text {opt. }}$ & Choice $1(\mathrm{n}=6, \mathrm{r}=1)$ & Choice $2(\mathrm{n}=5, \mathrm{r}=1.25)$ & Results difference \\
\hline Jan. & 55 & $24.13+5 * 13.12=89.75$ & $24.13+4 * 16.18=88.86$ & $1 \%$ \\
\hline Feb. & 50 & $25.63+5 * 17.04=110.85$ & $25.63+4 * 21.00=109.65$ & $1 \%$ \\
\hline Mar. & 35 & $26.67+5 * 21.81=135.73$ & $26.67+4 * 26.55=132.87$ & $2 \%$ \\
\hline Apr. & 20 & $27.79+5 * 26.16=158.58$ & $27.79+4 * 27.77=138.86$ & $12 \%$ \\
\hline May & 5 & $29.21+5 * 28.93=173.86$ & $29.21+4 * 29.21=146.04$ & $16 \%$ \\
\hline Jun. & 5 & $29.84+5 * 29.84=179.03$ & $29.84+4 * 29.84=149.19$ & $17 \%$ \\
\hline Jul. & 5 & $29.03+5 * 28.83=173.17$ & $29.03+4 * 29.02=145.10$ & $16 \%$ \\
\hline Aug. & 15 & $27.36+5 * 26.45=159.60$ & $27.36+4 * 27.34=136.72$ & $14 \%$ \\
\hline Sep. & 30 & $25.80+5 * 22.64=138.98$ & $25.80+4 * 25.79=128.98$ & $7 \%$ \\
\hline Oct. & 45 & $24.73+5 * 17.77=113.60$ & $24.73+4 * 21.83=112.03$ & $1 \%$ \\
\hline Nov. & 55 & $23.71+5 * 13.65=91.95$ & $23.71+4 * 16.82=90.97$ & $1 \%$ \\
\hline Dec. & 60 & $23.28+5 * 11.88=82.67$ & $23.28+4 * 14.65=81.90$ & $1 \%$ \\
\hline
\end{tabular}

